\title{
Smartphone Applications Providing Information about Stroke: Are We Missing Stroke Risk Computation Preventive Applications?
}

\author{
Melvyn WB Zhang, ${ }^{a}$ Roger CM Ho ${ }^{\mathrm{b}}$ \\ ${ }^{a}$ Centre for Healthcare Innovation \& Medical Engineering, Biomedical Institute for Global Health Research and Technology (BIGHEART), National \\ University of Singapore \\ ${ }^{b}$ Department of Psychological Medicine, Yong Loo Lin School of Medicine, National University of Singapore, Singapore
}

\section{Dear Sir:}

Dubey D et al. (2014) ${ }^{1}$ in their previous article provided a comprehensive overview of stroke smartphone applications. The authors have reviewed a cumulative total of 93 applications and highlighted that a good proportion of these smartphone applications have been conceptualized with the participation of a healthcare agency. ${ }^{1}$ The authors also reported that the vast majority of the application are targetted towards healthcare professionals instead of the general public, ${ }^{1}$ and recommended that future stroke applications should be jointly conceptualized by application developers with healthcare professionals. Whilst the previous review of stroke smartphone application was comprehensive, the authors failed to point out the paucity of stroke prevention applications, or stroke risk calculators that are available on the application store. This is of peritnent importance, given that reports released by the World Health Organization recently have highlighted that stroke accounts for approximately $9.6 \%$ of all mortality and stroke is in itself, a major public health issue, that warrants more preventive efforts. ${ }^{2}$ Public health efforts involve education of the general public about the associated risk factors, but more importantly, there ought to be avenues to which individuals in the general population could compute and have an awareness of their 5-year and 10-year projected risk of getting stroke. It is thus peritnent to determine whether such applications do exist, and whether these applications could address the issue of stroke prevention by computing the dynamic risk.
Instead of using the same search methodology done previously, ${ }^{1}$ the authors searched both the Apple and Android stores using the keywords "stroke prevention." A cumulative total of 130 applications were identified from the android store, out of which 5 were duplicated applications. 10 applications from the android store were considered and included in Table 1 to provide an overview of the existing stroke prevention applications, as the rest did not meet the inclusion criteria. From the Apple store, a cumulative total of 8 applications were identified, and 1 application which was duplicated was removed, resulting in 4 applications being included in Table 1. The inclusion criteria for the selection of these applications were limited to the relevance of the key words used for the search strategy as well as that the application needed to be in English language. The search strategy was conducted between the week of 25th to 30th July 2016. Table 1 provides an overview of the basic characteristics of the stroke prevention applications as well as the funtionalities that they include.

Most of the current stroke prevention applications that are available on the store provide general information about stroke as well as the risk factors that would predispose individuals towards stroke. There is to date only one application, that of 'Stroke RiskoMeter', that enables the computation of the risk of acquiring a stroke for a normal individual. Of note, the user who is using the application is required to key in and provide a response to indicate whether he or she has a particular static risk factor, and these include that of age, sex, race, family history of stroke, blood pressure medications, presence of existing heart conditions, pres- 
Table 1. Overview of stroke prevention applications extracted from android and apple store

\begin{tabular}{|c|c|c|c|c|c|c|c|c|}
\hline Name of application & Platform & $\begin{array}{l}\text { Free/Paid } \\
\text { Application }\end{array}$ & Ratings & $\begin{array}{c}\text { Total } \\
\text { downloads }\end{array}$ & $\begin{array}{c}\text { Target } \\
\text { audience }\end{array}$ & $\begin{array}{l}\text { Education } \\
\text { information }\end{array}$ & Risk computation & $\begin{array}{c}\text { Heatlcare } \\
\text { agenices } \\
\text { invovlement }\end{array}$ \\
\hline Af-stroke & Android & Free & 4.5 & $10,000+$ & $\begin{array}{l}\text { Patients (With atrial } \\
\text { fibrillation }\end{array}$ & Nil & $\begin{array}{l}\text { Presence of risk } \\
\text { calculators (Like } \\
\text { CHDA2) to compute } \\
\text { risk }\end{array}$ & No \\
\hline Stroke risometer & Android & $\begin{array}{l}\text { Free (with in-app } \\
\text { purchases) }\end{array}$ & 3.4 & $10,000+$ & General public & Yes & Yes & Yes \\
\hline Stroke disease & Android & Free & 4.6 & 500 & General public & Yes & No & No \\
\hline Stroke prevention helicon guide & Android & Free & NA & $10+$ & General public & Yes & No & No \\
\hline Stroke patient & Android & Free & 4.5 & 5000 & General public & Yes & No & No \\
\hline Thrombsis control & Android & Free & 4.5 & 1000 & General public & Yes & No & Yes \\
\hline Rcp stroke guidelines & Android & $\$ 1.93$ & NA & 100 & Healthcare providers & Yes & No & No \\
\hline Abc of stroke & Android & $\$ 37.42$ & NA & NA & General public & Yes & No & No \\
\hline Faqs on stroke & Android & $\begin{array}{l}\text { Free (with in-app } \\
\text { purchases) }\end{array}$ & 3.0 & NA & General public & Yes & No & Yes \\
\hline Stroke disease and symptoms & Android & Free & NA & NA & General public & Yes & No & No \\
\hline $\begin{array}{l}\text { Stroke prevention in atrial } \\
\text { fibrillation }\end{array}$ & Apple & Free & NA & NA & Clinicians & Yes & No & Yes \\
\hline Stroke patient & Apple & Free & NA & NA & Patients & Yes & No & No \\
\hline $\begin{array}{l}\text { Rep stroke guideline 2012- } \\
\text { patient and carer }\end{array}$ & Apple & Free & NA & NA & $\begin{array}{l}\text { Patients and care } \\
\text { giver }\end{array}$ & Yes & No & Yes \\
\hline Stroke riskometer & Apple & Free & NA & NA & Patients & Yes & Yes & Yes \\
\hline
\end{tabular}

NA, not applicable.

ence of left ventricular hypertrophy, atrial fibrillation, dementia, prior traumatic brain injury as well as prior stroke. Other dynamic risk factors that the individual needs to provide an input are with regards to the their existing body mass index, whether he or she is smoking and using alcohol, the amount of fruit and vegatables consumption, levels of physical activities as well as their existing systolic blood pressure and whether they have been diagnosed with diabetes mellitus. One of the major limitations with the current prognostic tool is that the application relies heavily on self-reported information and does not capture objective information. Dynamic risk factors such as physical activity levels and blood pressure could be trended and captured using the inherent smartphone sensors. If stroke prevention smartphone applications could allow the real-time trending of dynamic risk factors and compute and provide individuals with an awareness of their dynamic risk, that would be great in terms of reminding individuals that they do need to take action on some of their risk factors, in order to mitigate their levels of risk.

Thus, aside from the recommendation that there ought to be more healthcare professionals involvement in the conceptualization and the development of stroke smartphone applications, it is peritent for healthcare professionals to consider the development of dynamic stroke prevention tools that could inform individuals about their risk of acquiring stroke and remind them to take action on some of their risk factors.

\section{References}

1. Dubey D, Amritphale A, Sawhney A, Amritphale N, Dubey $P$, Pandey A. Smart phone applications as a source of information on stroke. J Stroke. 2014;16:86-90.

2. Thomas T, Stephen B, Colin M. The global burden of cerebrovascular disease. http://www.who.int/healthinfo/statistics/bod_ cerebrovascular diseasestroke.pdf. Last assessed on 31st Juyl 2016.

Correspondence: Melvyn Zhang

Centre for Healthcare Innovations \& Medical Engineering Biomedical Institute for Global Health Research and Technology (BIGHEART), National University of Singapore, MD6, 14 Medical Drive, \#14-01, Singapore 117599

Tel: +65-63892504, Fax: +65-63892222

Email: melvynzhangweibin@gmail.com

Received: July 31, 2016

Revised: August 22, 2016

Accepted: August 22, 2016

The authors have no financial conflicts of interest 